\title{
Properties of high performance concrete: the effect of cracks
}

\author{
E. Mňahončáková, M. Jiřičková \& R. Černý \\ Department of Structural Mechanics, Faculty of Civil Engineering, \\ Czech Technical University in Prague, Czech Republic
}

\begin{abstract}
The moisture transport and storage parameters of high performance concrete belong to the most critical parameters in designing and using complex reliability based models for service life prediction of concrete structures. However, mostly it is supposed that the material is compact without any significant cracks, which is not always true. In this paper, the effect of thermally induced cracks on the basic moisture transport and storage properties is analyzed. Experimental results show that the presence of cracks in hardened high performance concrete mixtures dramatically changes all measured hygric parameters. Also, the effects of both microsilica and the size and presence of aggregates on moisture transport and storage parameters are very important. The liquid water transport is found to be affected by cracks, microsilica and aggregates in a much more significant way than water vapour transport.

Keywords: high performance concrete, moisture transport and storage properties, cracks.
\end{abstract}

\section{Introduction}

The progressive building materials development improves their quality and utility value. In order to achieve better material properties, besides the new technologies also specific admixtures are employed. The accurate admixtures dosage and technological conditions observation can improve the material parameters like strength and durability. Most frequently, the mineral admixtures, for example pozzolana, fly ash or flue cinder, are used in concrete production. Fine siliceous materials usually called silica fume belong to relatively newly applied materials improving concrete quality. 
Silica fume can influence the hydration process on the one hand physically, ultra fine elements fill space between hydrating cement grains, on the other one chemically; they can react together with calcium hydroxide to form qualitatively different binding products. It leads to lower porosity, it changes the micro-pores distribution, the cementing agent is compacting and the strength, insolubility and corrosion durability of final product are improved.

Despite the gradual shift in the HPC design and application philosophy towards a generally recognized necessity to measure a wider scale of HPC parameters the mechanical properties still remain the far most frequent parameters investigated in the research work being done on HPC. Water and water vapor transport and storage properties of HPC were not yet in the center of interest of most researchers until now although they possess a very high predicative potential concerning the HPC quality.

In this paper, we analyse the influence of cracks on moisture transport and storage parameters of two different types of concrete, namely the high performance concrete C90/105 containing microsilica and the same material C60/75 without microsilica.

\section{Materials}

Basic tested material was high performance concrete C90/105 containing silica fume suspension, microsilica, denoted as BI in subsequent text. For the sake of comparison, the same concrete mixture $\mathrm{C} 60 / 75$ (denoted as $\mathrm{BII}$ ) was prepared without microsilica. In order to analyse the effect of aggregates on moisture transport and storage parameters, two other mixtures based on BI and BII were prepared. The first one (denoted as BBI and BBII) was cement mortar without the $8-16 \mathrm{~mm}$ aggregate fraction. The second one was cement paste denoted as PI and PII. Table 1 presents the composition of the studied cement mixtures.

Table 1: $\quad$ Composition of studied cement mixtures.

\begin{tabular}{|c|c|c|c|c|c|c|c|c|}
\hline \multirow{3}{*}{$\begin{array}{l}\text { Type of } \\
\text { concrete }\end{array}$} & \multicolumn{8}{|c|}{ Composition in $\mathrm{g}$} \\
\hline & \multirow{2}{*}{$\begin{array}{l}\text { CEM I } \\
52.5 \mathrm{R}\end{array}$} & \multirow{2}{*}{$\begin{array}{c}{ }^{*} \mathrm{SiO}_{2} \\
\text { suspen- } \\
\text { sion }\end{array}$} & \multicolumn{3}{|c|}{ Aggregates } & \multirow{2}{*}{$\begin{array}{c}{ }^{* *} \text { Woer- } \\
\text { ment } \\
\text { FM } 794\end{array}$} & \multirow{2}{*}{$\begin{array}{c}{ }^{* * *} \text { Lentan } \\
\text { VZ } 33\end{array}$} & \multirow[b]{2}{*}{$\mathrm{w} / \mathrm{c}$} \\
\hline & & & $\begin{array}{c}0-4 \\
\mathrm{~mm}\end{array}$ & $\begin{array}{l}4-8 \\
\mathrm{~mm}\end{array}$ & $\begin{array}{c}8-16 \\
\mathrm{~mm}\end{array}$ & & & \\
\hline BI & 480 & 72 & 664 & 207 & 995 & 7.74 & 2.58 & 0.36 \\
\hline BII & 470 & 0 & 668 & 209 & 1001 & 5.17 & 2.35 & 0.33 \\
\hline BBI & 480 & 72 & 664 & 1202 & 0 & 7.74 & 2.58 & 0.38 \\
\hline BBII & 470 & 0 & 668 & 1210 & 0 & 5.17 & 2.35 & 0.35 \\
\hline $\mathrm{PI}$ & 2346 & 352 & 0 & 0 & 0 & 38 & 12.67 & 0.31 \\
\hline PII & 2348 & 0 & 0 & 0 & 0 & 26 & 12 & 0.34 \\
\hline
\end{tabular}

${ }^{*} \mathrm{SiO}_{2}$ suspension - water suspension consisting of $88-95 \%$ of $\mathrm{SiO} 2$ and small amounts of calcium oxide, magnesium oxide and nitrogen oxide.

${ }^{* *}$ FM 794 - plasticizer on the basis of polycarboxylateether.

${ }^{* * *}$ Lentan VZ 33 - hydration retarder on the saccharose basis. 
Each mixture was cast into the forms, after one day the samples were removed from the forms and then varnished using curing solution. After the hardening period of 28 days, the samples were cut to required dimensions. These samples were then heated up to $600^{\circ} \mathrm{C}$ in an oven to reach cracks, see Figure 1 .

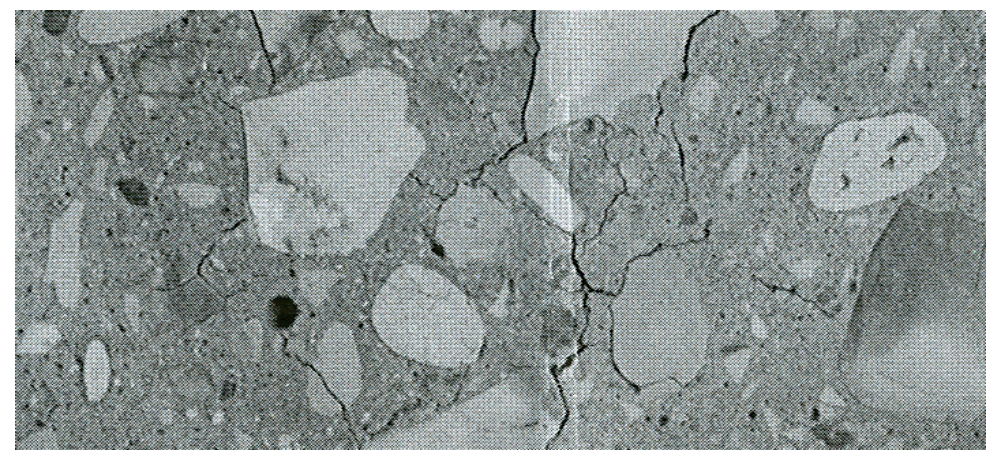

Figure 1: The HPC BI sample after thermal loading.

\section{Experimental methods}

\subsection{Basic material parameters}

As fundamental physical material characteristics, bulk density $\rho_{b}\left[\mathrm{kgm}^{-3}\right]$, vacuum saturation moisture content $w_{\text {sat }}\left[\mathrm{kgm}^{-3}\right]$, porosity [Vol.-\%] and matrix density $\rho_{m}\left[\mathrm{~kg} \mathrm{~m}^{-3}\right]$ were determined. They were obtained using the gravimetric method and the vacuum saturation method. The vacuum saturation moisture content was calculated according to the equation

$$
w_{s a t}=\rho_{w} \frac{m_{s a t}-m_{0}}{m_{s a t}-m_{a}}=\rho_{w} \psi,
$$

where $\rho_{w}$ is the water density $\left[\mathrm{kg} \mathrm{m}^{-3}\right], m_{0}, m_{s a t}$ and $m_{a}$ are the mass of dry sample, water- saturated sample and mass of the immersed water - saturated sample $[\mathrm{kg}]$, respectively, and $\psi$ is the open porosity, which is defined as the ratio of the volume of open pores in material to its total volume. Matrix density was calculated as

$$
\rho_{\text {mat }}=\frac{m_{0}}{V(1-\psi)},
$$

where $V$ is sample volume $\left[\mathrm{m}^{3}\right]$.

The measurement of basic parameters took place in a conditioned laboratory at the temperature of $22 \pm 1{ }^{\circ} \mathrm{C}$ and $25-30 \%$ relative humidity. Each result represents the average value from three to five measured values. 


\subsection{Water vapour and water transport parameters}

Two versions of the common cup method were employed in the measurements of the water vapor diffusion coefficient [1]. In the first one the sealed cup containing silica gel (5\% relative humidity) was placed in a controlled climatic chamber with $97 \%$ relative humidity and weighed periodically. In the second one the cup containing the saturated solution of $\mathrm{K}_{2} \mathrm{SO}_{4}$ (97\% relative humidity) was placed in the $25 \%$ relative humidity environment. The measurements were done at $20^{\circ} \mathrm{C}$ in a period of two weeks. The steady state values of mass gain or loss were determined by linear regression for the last five readings.

The water vapor diffusion coefficient $\mathrm{D}\left[\mathrm{m}^{2} \mathrm{~s}^{-1}\right]$ was calculated from the measured data according to the equation

$$
D=\frac{\Delta m \cdot d \cdot R \cdot T}{S \cdot \tau \cdot M \cdot \Delta p_{p}}
$$

where $\Delta \mathrm{m}$ the amount of water vapor diffused through the sample $[\mathrm{kg}], \mathrm{d}$ the sample thickness $[\mathrm{m}], \mathrm{S}$ the specimen surface $\left[\mathrm{m}^{2}\right], \tau$ the period of time corresponding to the transport of mass of water vapor $\Delta \mathrm{m}[\mathrm{s}], \Delta \mathrm{p}_{\mathrm{p}}$ the difference between partial water vapor pressure in the air under and above specific specimen surface $[\mathrm{Pa}], \mathrm{R}$ the universal gas constant, $\mathrm{M}$ the molar mass of water, $\mathrm{T}$ the absolute temperature $[\mathrm{K}]$.

On the basis of the diffusion coefficient $\mathrm{D}$, the water vapor diffusion resistance factor $\mu$ was determined:

$$
\mu=\frac{D_{a}}{D},
$$

where $D_{a}$ is the diffusion coefficient of water vapor in the air.

The water sorptivity was measured using a standard experimental setup. The specimen was water and vapor-proof insulated on four edges and the face side was immersed 1-2 $\mathrm{mm}$ in the water, constant water level in tank was achieved by a Mariott bottle with two capillary tubes. One of them, inside diameter $2 \mathrm{~mm}$, was ducked under the water level, second one, inside diameter $5 \mathrm{~mm}$, was above water level. The automatic balance allowed recording the increase of mass. The water absorption coefficient $A\left[\mathrm{kgm}^{-2} \mathrm{~s}^{-1 / 2}\right]$ was then calculated using the formula

$$
i=A \cdot \sqrt{t},
$$

where $i$ is the cumulative water absorption $\left[\mathrm{kg} / \mathrm{m}^{2}\right], t$ is the time from the beginning of the suction experiment. The water absorption coefficient was then employed for the calculation of the apparent moisture diffusivity in the form [2] 


$$
\kappa_{a p p} \approx\left(\frac{A}{w_{c}-w_{0}}\right)^{2}
$$

where $w_{c}$ is the saturated moisture content $\left[\mathrm{kgm}^{-3}\right]$ and $w_{0}$ the initial moisture content $\left[\mathrm{kgm}^{-3}\right]$.

In the experimental work, the following samples were used: water vapor diffusion coefficient -10 cylinders with the diameter $105 \mathrm{~mm}$ and thickness 20 $\mathrm{mm}$, water sorptivity -5 specimens $50 \times 50 \times 20 \mathrm{~mm}$.

\subsection{Sorption isotherms}

The water adsorption and desorption in a porous material are based on van der Waals forces between the surface of the porous matrix and water molecules. The dry material mass increases after a contact with moist air because of gradual bonding of water molecules from the air to the pore walls, in the case of adsorption. Desorption is reversed physical phenomenon, the initial state is capillary saturated sample. At the moment of achieving the equilibrium state between the water vapour pressure in the moist material and in the surrounding air this process is stopped.

The mass of samples was measured in specified periods of time until steady state value of mass was achieved. Then, the moisture content by mass was calculated according to the equation

$$
u_{m}=\frac{m_{w}-m_{0}}{m_{0}} \quad,
$$

where $m_{w}$ is the mass of wet sample and $m_{0}$ is the mass of dry sample [kg].

The samples were placed into the desiccators with different salt solutions to simulate different values of relative humidity, see Table 2.

Table 2: Relative humidity over saturated salt solutions.

\begin{tabular}{|l|c|c|c|}
\hline \multirow{2}{*}{ Salt } & \multicolumn{3}{|c|}{ Temperature/Relative humidity [-] } \\
\cline { 2 - 4 } & $20^{\circ} \mathrm{C}$ & $23^{\circ} \mathrm{C}$ & $25^{\circ} \mathrm{C}$ \\
\hline $\mathrm{LiCl}$ & 0.111 & - & 0.111 \\
\hline $\mathrm{MgCl}_{2} \cdot 6 \mathrm{H}_{2} \mathrm{O}$ & 0.330 & 0.329 & 0.328 \\
\hline $\mathrm{NaNO}_{2}$ & 0.654 & - & 0.643 \\
\hline $\mathrm{NaCl}$ & 0.755 & 0.754 & 0.753 \\
\hline $\mathrm{NH}_{4} \mathrm{Cl}$ & 0.792 & 0.788 & 0.786 \\
\hline $\mathrm{KCl}_{\mathrm{K}_{2} \mathrm{SO}_{4}}$ & 0.851 & 0.845 & 0.843 \\
\hline
\end{tabular}

In the measurements of adsorption and desorption isotherms, for each relative humidity 3-10 test specimens of each material with overall dimensions of $40 \mathrm{x}$ $40 \times 10 \mathrm{~mm}$ were prepared. The measurements were done at $23 \pm 1^{\circ} \mathrm{C}$. The initial 
states were dry samples in the case of adsorption, and capillary saturated samples in the case of desorption.

\section{Experimental results and discussion}

The results of basic parameter measurements are presented in Table 3.

Table 3: $\quad$ Basic material parameters.

\begin{tabular}{|l|c|c|c|c|c|c|c|c|}
\hline \multirow{2}{*}{$\begin{array}{l}\text { Type of } \\
\text { mixture }\end{array}$} & \multicolumn{4}{|c|}{ Without cracks } & \multicolumn{4}{c|}{ With cracks } \\
\cline { 2 - 10 } & $\rho_{b}$ & $\rho_{\text {mat }}$ & $w_{\text {sat }}$ & $\psi$ & $\rho_{b}$ & $\rho_{\text {mat }}$ & $w_{\text {sat }}$ & $\psi$ \\
\cline { 2 - 9 } & \multicolumn{3}{|c|}{$\left[\mathrm{kgm}^{-3}\right]$} & {$[\%]$} & \multicolumn{3}{c}{$\left[\mathrm{kgm}^{-3}\right]$} & {$[\%]$} \\
\hline BI & 2423 & 2760 & 122.0 & 12.20 & 2391 & 2856 & 162.2 & 16.30 \\
\hline BII & 2388 & 2647 & 95.1 & 9.80 & 2350 & 2713 & 133.2 & 13.40 \\
\hline BBI & 2240 & 2652 & 150.6 & 15.60 & 2147 & 2627 & 182.0 & 18.30 \\
\hline BBII & 2210 & 2578 & 140.5 & 14.30 & 2205 & 2669 & 174.8 & 17.40 \\
\hline PI & 1988 & 2809 & 248.4 & 29.20 & 1942 & 3068 & 375.8 & 36.70 \\
\hline PII & 1991 & 2779 & 285.2 & 28.30 & 2019 & 3088 & 355.7 & 34.60 \\
\hline
\end{tabular}

The highest bulk density exhibited the hardened HPC mixture BI. The second highest had the BII mixture without microsilica. Nearly the same values had mixtures denoted BBI and BBII, cement pastes had the lowest values. The bulk density of cement mixtures with cracks was lower then of the same without cracks. The matrix densities differed only in the range of about $5 \%$ and increased about $10 \%$ in the case of mixtures with cracks compared to mixtures without cracks. The highest vacuum saturated moisture content had the cement pastes PI and PII, where the difference was within the error range, and increased about $30 \%$ in the case of mixtures with cracks compared to mixtures without cracks. The most porous materials were cement pastes PI and PII, the presence of microsilica and admixtures did not have a significant effect. The porosity increased from 3 to $6 \%$ in the case of mixtures with cracks compared to mixtures without cracks.

The results of measurements of water and water vapour transport parameters of the studied hardened cement mixtures are presented in Tables 4 and 5.

The water vapour diffusion coefficient was affected by the addition of microsilica only for cement paste PI in a remarkable way where it decreased three to four times. However, for the mixture BII its effect was within the error range of the measuring method. The cracks caused dramatic increase of the water vapour diffusion coefficient in all cases.

The effect of microsilica on the liquid moisture transport parameters was more pronounced than on water vapour transport. The water sorptivity for the 
basic mixture BI decreased five times due to the microsilica addition, and for the cement paste PI by about 30\%. The moisture diffusivity of mixtures with microsilica decreased in a corresponding way. In the case of cement mixtures with cracks the moisture diffusivity increased one order of magnitude compared to mixtures without cracks.

Table 4: $\quad$ Water vapour transport properties of cement mixtures.

\begin{tabular}{|c|c|c|c|c|c|c|c|c|}
\hline \multirow{3}{*}{$\begin{array}{c}\text { Type } \\
\text { of } \\
\text { mixture }\end{array}$} & \multicolumn{4}{|c|}{ Without cracks } & \multicolumn{4}{|c|}{ With cracks } \\
\hline & \multicolumn{2}{|c|}{$D\left[10^{-6} \mathrm{~m}^{2} \mathrm{~s}^{-1}\right]$} & \multicolumn{2}{|c|}{$\mu[-]$} & \multicolumn{2}{|c|}{$D\left[10^{-6} \mathrm{~m}^{2} \mathrm{~s}^{-}\right.$} & \multicolumn{2}{|c|}{$\mu[-]$} \\
\hline & $\begin{array}{c}97- \\
25 \% \\
\text { RH }\end{array}$ & $\begin{array}{c}5- \\
97 \% \\
\text { RH }\end{array}$ & $\begin{array}{c}97- \\
25 \% \\
\text { RH }\end{array}$ & $\begin{array}{c}5- \\
97 \% \\
\text { RH }\end{array}$ & $\begin{array}{c}97- \\
25 \% \\
\text { RH }\end{array}$ & $\begin{array}{c}5- \\
97 \% \\
\text { RH }\end{array}$ & $\begin{array}{c}97- \\
25 \% \\
\text { RH }\end{array}$ & $\begin{array}{c}5- \\
97 \% \\
\text { RH }\end{array}$ \\
\hline $\mathrm{BI}$ & 1.06 & 0.397 & 22.5 & 59.3 & 1.48 & 1.55 & 15.8 & 15.4 \\
\hline $\mathrm{BII}$ & 1.10 & 0.375 & 20.9 & 61.4 & 2.22 & 1.76 & 10.4 & 13.2 \\
\hline BBI & 0.287 & 0.132 & 80.3 & 175.4 & 1.73 & 1.96 & 13.8 & 12.3 \\
\hline BBII & 0.288 & 0.151 & 81.4 & 152.1 & 2.11 & 2.23 & 11.0 & 10.6 \\
\hline PI & 0.136 & 0.079 & 170.7 & 295.9 & 2.29 & 3.20 & 10.2 & 7.2 \\
\hline PII & 0.357 & 0.291 & 65.4 & 81.7 & 2.22 & 1.76 & 10.4 & 13.2 \\
\hline
\end{tabular}

Table 5: $\quad$ Water transport properties of cement mixtures.

\begin{tabular}{|c|c|c|c|c|}
\hline \multirow{2}{*}{$\begin{array}{c}\text { Type of } \\
\text { mixture }\end{array}$} & \multicolumn{2}{|c|}{ Without cracks } & \multicolumn{2}{c|}{ With cracks } \\
\cline { 2 - 5 } & $A\left[\mathrm{~kg} \mathrm{~m}^{-2} \mathrm{~s}^{-1 / 2}\right]$ & $\kappa_{a p p}\left[\mathrm{~m}^{2} \mathrm{~s}^{-1}\right]$ & $A\left[\mathrm{~kg} \mathrm{~m}^{-2} \mathrm{~s}^{-1 / 2}\right]$ & $\kappa_{a p p}\left[\mathrm{~m}^{2} \mathrm{~s}^{-1}\right]$ \\
\hline BI & $3.63 \mathrm{E}-03$ & $8.9 \mathrm{E}-10$ & $4.84 \mathrm{E}-02$ & $9.2 \mathrm{E}-08$ \\
\hline BII & $1.80 \mathrm{E}-02$ & $3.3 \mathrm{E}-09$ & $4.23 \mathrm{E}-02$ & $1.1 \mathrm{E}-07$ \\
\hline BBI & $1.76 \mathrm{E}-02$ & $1.5 \mathrm{E}-08$ & $8.08 \mathrm{E}-02$ & $2.5 \mathrm{E}-07$ \\
\hline BBII & $4.04 \mathrm{E}-02$ & $8.3 \mathrm{E}-08$ & $6.21 \mathrm{E}-02$ & $2.0 \mathrm{E}-07$ \\
\hline PI & $2.36 \mathrm{E}-02$ & $7.0 \mathrm{E}-09$ & $2.77 \mathrm{E}-01$ & $5.5 \mathrm{E}-07$ \\
\hline PII & $3.52 \mathrm{E}-02$ & $1.8 \mathrm{E}-08$ & $1.59 \mathrm{E}-01$ & $2.0 \mathrm{E}-07$ \\
\hline
\end{tabular}

The effect of aggregate presence was found to be quite different for liquid water transport than for water vapour transport. The water sorptivity was for the basic hardened HPC mixture BI several times lower than for the cement pastes. On the other hand, the water vapour diffusion coefficient of cement pastes was always lower than for the basic hardened HPC mixtures. The 5-97\% RH values of the water vapour diffusion coefficient were always lower than the $97-25 \% \mathrm{RH}$ values, which is in accordance with the previous measurements on many other materials including concretes and cement pastes.

Figure 2a-f shows the measured adsorption (lower curves) and desorption (upper curves) isotherms. We can see that cement pastes had higher water adsorption capacity than the basic hardened HPC mixtures. This is an expected behaviour due to absence of the inert aggregates in cement pastes. The presence of microsilica slightly increased the water adsorption capacity of basic hardened 
HPC mixture but for cement pastes an opposite behaviour was observed. Therefore, any clear effect of microsilica on water adsorption capacity was not evidenced. The sorption curves are almost the same for the mixtures without and with cracks.

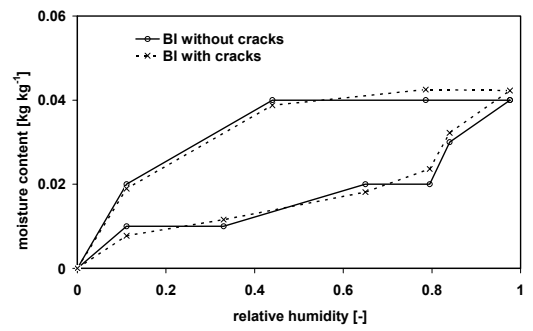

(a)

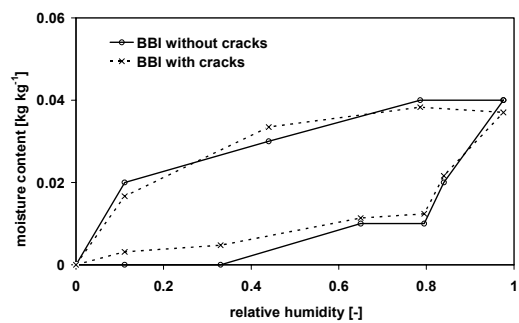

(c)

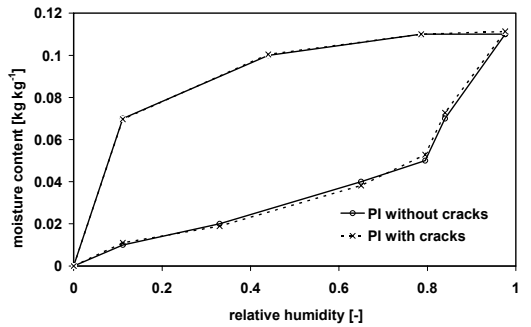

(e)

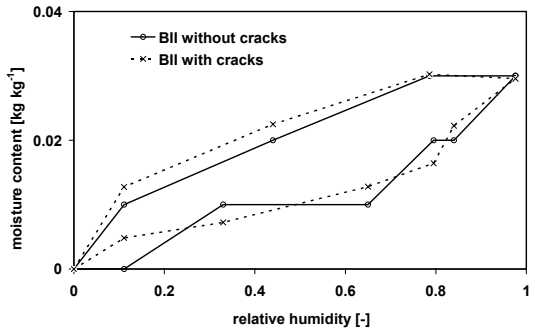

(b)

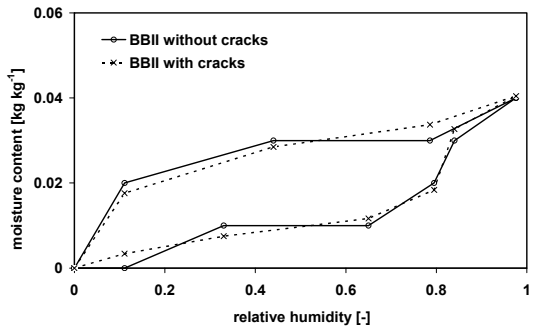

(d)

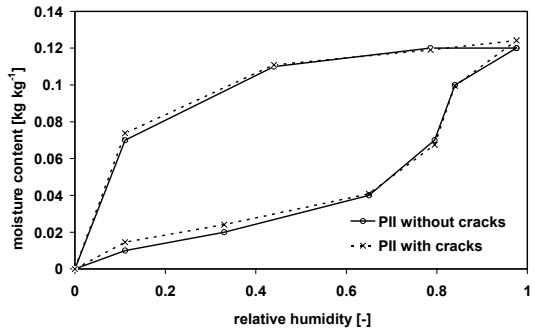

(f)

Figure 2: $\quad$ Sorption isotherm of mixture (a): BI, (b): BII, (c): BBI, (d): BBII, (e): PI and (f) PII.

\section{Conclusions}

The experimental work performed in this paper has shown that the presence of cracks in hardened HPC mixtures dramatically changed all measured parameters. Also the effect of both microsilica and aggregates on the moisture transport and storage parameters was very important. The liquid water transport was found to be affected by cracks, microsilica and aggregates in a much more significant way than water vapour transport. 


\section{Acknowledgement}

This research has been supported by the Ministry of Education of Czech Republic, under grant No. MSM: 6840770003.

\section{References}

[1] S. Roels, J. Carmeliet, H. Hens, O. Adan, H. Brocken, R. Černý, Z. Pavlík, C. Hall, K. Kumaran, L. Pel, R. Plagge, Interlaboratory Comparison of Hygric Properties of Porous Building Materials. Journal of Thermal Envelope and Building Science 27(2004), 307-325.

[2] R. Černý, J. Poděbradská, J. Drchalová, Water and water vapor penetration through coatings. Journal of Thermal Envelope and Building Science 26(2002), 165-177. 